\title{
The Impact of Pediatric Palliative Care Education on Medical Students' Knowledge and Attitudes
}

\author{
Aleksandra Korzeniewska-Eksterowicz, ${ }^{1,2}$ Lukasz Przysło, ${ }^{1,2}$ Bogna Kędzierska, ${ }^{3}$ \\ Małgorzata Stolarska, ${ }^{2,4}$ and Wojciech Młynarski ${ }^{4}$ \\ ${ }^{1}$ Pediatric Palliative Care Unit, Department of Pediatrics, Oncology, Hematology and Diabetology, Medical University of Lodz, \\ 36/50 Sporna Street, 91-738 Łodz, Poland \\ ${ }^{2}$ Gajusz Foundation, Pediatric Palliative Care Center, Home Hospice for Children of Lodz Region, 87 Dąbrowskiego Street, \\ 93-271 Lodz, Poland \\ ${ }^{3}$ Institute of Psychology, University of Lodz, 10/12 Smugowa Street, 91-433 Lodz, Poland \\ ${ }^{4}$ Department of Pediatrics, Oncology, Hematology and Diabetology, Medical University of Lodz, 36/50 Sporna Street, \\ 91-738 Łodz, Poland
}

Correspondence should be addressed to Aleksandra Korzeniewska-Eksterowicz; aleksandra.korzeniewska-eksterowicz@umed.lodz.pl

Received 9 August 2013; Accepted 7 October 2013

Academic Editors: S. Bertelloni, T. Kendirli, and D. C. Van der Zee

Copyright (C) 2013 Aleksandra Korzeniewska-Eksterowicz et al. This is an open access article distributed under the Creative Commons Attribution License, which permits unrestricted use, distribution, and reproduction in any medium, provided the original work is properly cited.

\begin{abstract}
Purpose. Most undergraduate palliative care curricula omit pediatric palliative care (PPC) issues. Aim of the study was to evaluate the pilot education programme. Methods. All 391 students of Faculty of Medicine (FM) and 59 students of Division of Nursing (DN) were included in anonymous questionnaire study. Respondents were tested on their knowledge and attitude towards PPC issues before and at the end of the programme and were expected to evaluate the programme at the end. Results. For final analysis, authors qualified 375 double forms filled in correctly (320 FM and $55 \mathrm{DN}$ ). Before the programme, students' knowledge assessed on 0-100-point scale was low (FM: median: 43.35 points; $25 \%-75 \%$ : (40p-53.3p); DN: $26.7 \mathrm{p} ; 13.3 \mathrm{p}-46.7 \mathrm{p}$ ), and, in addition, there were differences $(P<0.001)$ between both faculties. Upon completion of the programme, significant increase of the level of knowledge in both faculties was noted (FM: 80p; 73.3-100; DN: 80p; 66.7p-80p). Participation in the programme changed declared attitudes towards some aspects of withholding of special procedures, euthanasia, and abortion. Both groups of students positively evaluated the programme. Conclusions. This study identifies medical students' limited knowledge of PPC. Educational intervention changes students' attitudes to the specific end-of-life issues. There is a need for palliative care curricula evaluation.
\end{abstract}

\section{Introduction}

In the majority of Polish medical universities, palliative medicine is a part of the teaching programme [1]. However, most programmes in Poland and worldwide include only adult palliative care [1-8]. Gibbins et al. [6] suggest that $86 \%$ of medical curriculum omits PPC. There are scarce literature reports on teaching programmes within pediatric palliative care (PPC) [9-11]. In Poland, PPC has been mainly provided by specialized pediatric palliative home care teams, for example, home hospices [12-14]. Currently, there are almost 40 pediatric home hospices and, in the years 2000 2010, the number of treated children had increased more than fivefold [14]. Despite dynamic development of the PPC, there are difficulties in staff recruitment and significant deficits in the knowledge about PPC. These difficulties arise as a result of a lack of PPC training among medical students.

Pediatric Palliative Care Unit is the first academic unit in Poland which implemented teaching of PPC and developed the first pilot training programme in the field of PPC in Poland.

PPC became a part of the general obligatory pediatrics curriculum. It applies to final year medical students (Faculty of Medicine, FM) and 3rd year nursing students (Division of Nursing, DN). The module for FM consists of two days of 
compulsory lectures (5 hours) and workshops (5 hours). The module for DN consists of 5 hours of compulsory lectures. During the first day, students are divided into groups of 10-12 people. The second day (only for FM students) takes a form of workshops (in groups of 5-6 students) divided into two parts: clinical and psychological. Clinical workshops focus on detailed case studies of hospice patients. The students are given written materials with 18 case studies. Due to the fact that the patients stay at home, where the hospice team visits them, their active participation in the training was logistically not possible.

Aim of the study was to examine whether the programme will have a significant effect upon students' knowledge and attitude towards PPC issues and to evaluate the feedback of students who participated in the education programme.

\section{Material and Methods}

All students participating in the programme were included in our study (391 FM students and 59 DN students).

2.1. Evaluation of Students' Knowledge and Attitude. We conducted an anonymous questionnaire study. Respondents filled in identical forms before and after completion of the programme. The questionnaire covered selected social and demographic data and 28 closed questions evaluating the knowledge and attitude of students towards the PPC. Nine questions concerned scientific PPC issues, and the remaining questions concerned attitudes of respondents towards selected aspects of PPC, including their attitude towards special procedures, euthanasia, and abortion.

In 9 questions evaluating the knowledge of students, each correct answer scored 1 point, which gave 15 points maximum (some questions were multichoice questions). During analysis, the results were standardized by transforming the raw results onto a 100-grade scale (0-100 points).

\subsection{Evaluation of Students' Satisfaction from the Programme.} The participants were expected to evaluate the education programme in the form of an anonymous questionnaire given to them at the end of the programme. The questionnaire designed for the purpose of that research consisted of 10 closed and 4 open questions. Closed questions covered the following issues: form and structure of the programme, lectures and workshop evaluation, content evaluation, usefulness of subject and its relevancy to the practical and academic work, and assessment of the tutors and the conspectus given to the students. The students were expected to assess each aspect of the programme on a $0-6$-point scale, where 0 indicated complete lack of satisfaction and 6 complete satisfaction. The open questions gave students a chance to freely express their opinions and reflections as well as suggest which aspects of the programme were unnecessary or missing. Student's evaluation was voluntary and did not affect their assessment.

2.2.1. Statistical Analysis. Continuous variables of paired observations were performed by Wilcoxon test or $t$-test

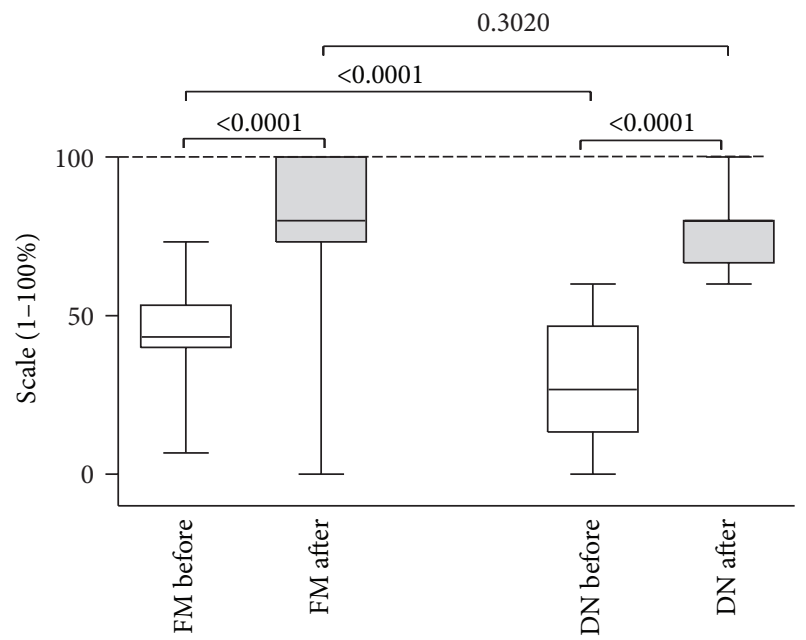

FM: Faculty of Medicine DN: Division of Nursing

Figure 1: The level of knowledge of Faculty of Medicine students (left panel) and Division of Nursing students (right panel) before and after completion of the obligatory programme.

depending on variable distribution. Post hoc comparisons were performed with Tukey's HSD test if statistical significance was noted in analysis of variance (ANOVA). Noncontinuous variables were studied using chi-square test with corrections for multiple comparisons. A $P$ value $<0.05$ was considered as statistically significant. STATISTICA 10.0 (Statsoft, Tulsa, OK, USA) software was used for statistical analysis. The study was approved by the Ethics Committee of Medical University of Lodz (RNN/136/10/KE).

\section{Results}

3.1. Evaluation of Knowledge and Attitudes of Students. All students participating in the programme completed the questionnaires; for final analysis, we qualified 375 double forms filled in correctly (320 FM and 55 DN). Social and demographic characteristics of respondents are presented in Table 1 .

Before the programme, the knowledge of students from both faculties on PPC was low (FM: median: 43.35 points (p), 25\%-75\%: (40p-53.3p); DN: median: $26.7 \mathrm{p}, 25 \%-75 \%$ : $(13.3 p-46.7 p))$, and, in addition, there were statistically significant $(P<0.001)$ differences between both faculties. Upon completion of the programme, statistically significant increase of the level of knowledge in both faculties was noted (FM: median: 80p, 25\%-75\%: 73.3-100; DN: median: 80, 25\%-75\%: 66.7-80), as shown in Figure 1.

Before the programme, both groups of students had great problems with questions concerning the structure of patients referred for palliative care and criteria of morphine use in children. Only 6\% of FM students knew that the largest group of hospice care children constitute those with neurological diseases, and none from DN students gave proper answer. The most common choice was oncological disease ( $81 \%$ versus 
TABLE 1: Social and demographic characteristics of respondents.

\begin{tabular}{|c|c|c|c|c|}
\hline & \multicolumn{2}{|c|}{ Faculty of Medicine students, $n=320$} & \multicolumn{2}{|c|}{ Division of Nursing students, $n=55$} \\
\hline & $n$ & $\%$ & $n$ & $\%$ \\
\hline \multicolumn{5}{|l|}{ Gender } \\
\hline Female & 105 & $32.8 \%$ & 0 & $0 \%$ \\
\hline Male & 215 & $67.2 \%$ & 55 & $100 \%$ \\
\hline \multicolumn{5}{|l|}{ Place of living } \\
\hline Rural & 39 & $12.5 \%$ & 7 & $12.7 \%$ \\
\hline Small town $(<100.000$ inhabitants $)$ & 66 & $21.2 \%$ & 12 & $21.8 \%$ \\
\hline Town $(100-500.000)$ & 37 & $11.9 \%$ & 7 & $12.7 \%$ \\
\hline Big city $(>500.000)$ & 170 & $54.5 \%$ & 29 & $52.7 \%$ \\
\hline \multicolumn{5}{|l|}{ Having children } \\
\hline Yes & 265 & $83.1 \%$ & 48 & $87.3 \%$ \\
\hline No & 54 & $16.9 \%$ & 7 & $12.7 \%$ \\
\hline \multicolumn{5}{|l|}{ Parents' education level } \\
\hline Primary & 4 & $1.3 \%$ & 12 & $21.8 \%$ \\
\hline Secondary & 105 & $34.0 \%$ & 24 & $43.6 \%$ \\
\hline Academic & 200 & $64.7 \%$ & 19 & $34.5 \%$ \\
\hline \multicolumn{5}{|l|}{ Medical profession in close family } \\
\hline Physician & 105 & $32.8 \%$ & 0 & $0 \%$ \\
\hline Nurse & 14 & $4.4 \%$ & 10 & $18.2 \%$ \\
\hline Pharmacist & 11 & $3.4 \%$ & 0 & $0 \%$ \\
\hline Others & 22 & $6.9 \%$ & 0 & $0 \%$ \\
\hline \multicolumn{5}{|l|}{ Religion } \\
\hline Catholic & 278 & $87.1 \%$ & 48 & $87.3 \%$ \\
\hline Protestant & 1 & $0.3 \%$ & 0 & $0 \%$ \\
\hline Orthodox & 0 & $0 \%$ & 0 & $0 \%$ \\
\hline Muslim & 0 & $0 \%$ & 0 & $0 \%$ \\
\hline Atheist & 35 & $11 \%$ & 7 & $12.7 \%$ \\
\hline Others & 5 & $1.6 \%$ & 0 & $0 \%$ \\
\hline
\end{tabular}

$65 \%)$. After the programme, the majority of students $P<$ 0.001 gave correct answer (94\% versus $91 \%$ ). Before the programme, $24.4 \%$ of FM and $43.6 \%$ of DN students thought that morphine is contraindicated in treatment of newborns. After the programme, the majority of students ( $97.5 \%$ versus $100 \%)$ gave correct answer $(P<0.001)$. Before education, only $7.8 \%$ of FM and $9.1 \%$ of DN students knew inhaled way of morphine application and after the programme, most of them $(74.6 \%$ versus $72.7 \%)$ gave proper answer $(P<$ 0.001 ). Additionally, up to $48.1 \%$ of FM and $65.5 \%$ of DN students indicated respiratory depression as most common complication of treatment; after the education, that answer was indicated only by $7.2 \%$ of FM and $7.3 \%$ of DN students.

The questionnaire included students' opinion on specific problems of PPC, including withholding of special procedures, euthanasia, and abortion, Table 2 and Figure 2. The students listed acceptable, according to them, reasons for abortion. There were no differences between the students' groups and participation in the programme did not change their declared attitudes, Figure 2(a). Students were asked what they would do if a lethal defect would be detected in their child during prenatal diagnostics, Figure 2(b).

3.2. Evaluation of Students' Satisfaction from the Programme. The questionnaires were filled in by all participants; eventually, 383 properly filled forms were analyzed (336 FM and $47 \mathrm{DN})$.

Both groups of students positively evaluated the programme. Mean overall assessment was 4.85 (FM) and 5.02 (DN) points; form of the programme assessment was, respectively, 4.87 and 4.83 , structure of the programme was 5.03 and 4.97, conspectus given to the students was 5.68 and 5.85, lectures were 4.87 and 4.92 , and workshop evaluation was 4.79 (FM only).

For the majority of participants, the knowledge obtained during the programme was new, Figure 3(a). The respondents were asked how useful the new knowledge will be in their future work and preparation for exams; they evaluated the 
TABLE 2: Students' opinion on specific problems of palliative care before and after education programme.

\begin{tabular}{|c|c|c|c|c|c|c|c|c|}
\hline \multirow[t]{2}{*}{ Question and answer's option } & \multicolumn{2}{|c|}{$\begin{array}{l}\text { Percentage of } \\
\text { indicated answers by } \\
\text { Faculty of Medicine } \\
\text { students }\end{array}$} & \multirow[t]{2}{*}{$\begin{array}{l}P \text { value* within } \\
\text { the group }\end{array}$} & \multicolumn{2}{|c|}{$\begin{array}{l}\text { Percentage of } \\
\text { indicated answers by } \\
\text { Division of Nursing } \\
\text { students }\end{array}$} & \multirow[t]{2}{*}{$\begin{array}{l}P \text { value* within } \\
\text { the group }\end{array}$} & \multicolumn{2}{|c|}{$\begin{array}{l}P \text { value }{ }^{*} \text { between } \\
\text { the groups }\end{array}$} \\
\hline & Before & After & & Before & After & & Before & After \\
\hline \multicolumn{9}{|l|}{$\begin{array}{l}\text { Are there situations when } \\
\text { resuscitation of } \\
\text { a child may not be initiated? }\end{array}$} \\
\hline Yes & 91.3 & 98.1 & & 56.4 & 100 & & & \\
\hline No & 2.2 & 0.6 & 0.001 & 25.5 & 0 & $<0.001$ & $<0.001$ & 0.588 \\
\hline I do not know & 6.6 & 1.3 & & 18.2 & 0 & & & \\
\hline \multicolumn{9}{|l|}{$\begin{array}{l}\text { Would you decide on euthanasia } \\
\text { act in a patient? }\end{array}$} \\
\hline Yes & 11.5 & 9.5 & \multirow{2}{*}{0.419} & 21.8 & 9.1 & \multirow{2}{*}{0.065} & \multirow{2}{*}{0.035} & \multirow{2}{*}{0.925} \\
\hline No & 88.5 & 90.5 & & 78.2 & 90.9 & & & \\
\hline \multicolumn{9}{|c|}{$\begin{array}{l}\text { What would you choose in } \\
\text { situation of suffering from a } \\
\text { progressing, untreatable disease? }\end{array}$} \\
\hline Natural death & 59.7 & 75.4 & \multirow{3}{*}{$<0.001$} & 87.3 & 76.4 & \multirow{3}{*}{0.138} & \multirow{3}{*}{$<0.001$} & \multirow{3}{*}{0.1} \\
\hline Euthanasia & 28.4 & 17.9 & & 12.7 & 23.6 & & & \\
\hline Physician-assisted suicide & 11.8 & 6.7 & & 0 & 0 & & & \\
\hline \multicolumn{9}{|l|}{$\begin{array}{l}\text { Should be euthanasia legally } \\
\text { available in Poland? }\end{array}$} \\
\hline Yes & 2.5 & 3.5 & \multirow{3}{*}{0.048} & 0 & 3.6 & \multirow{3}{*}{0.009} & \multirow{3}{*}{$<0.001$} & \multirow{3}{*}{0.895} \\
\hline $\begin{array}{l}\text { Yes, but only if special criteria } \\
\text { had been fulfilled }\end{array}$ & 58.5 & 47.9 & & 28 & 52.7 & & & \\
\hline No & 39 & 48.6 & & 72 & 43.6 & & & \\
\hline
\end{tabular}

* Pearson's $\chi^{2}$ Test.

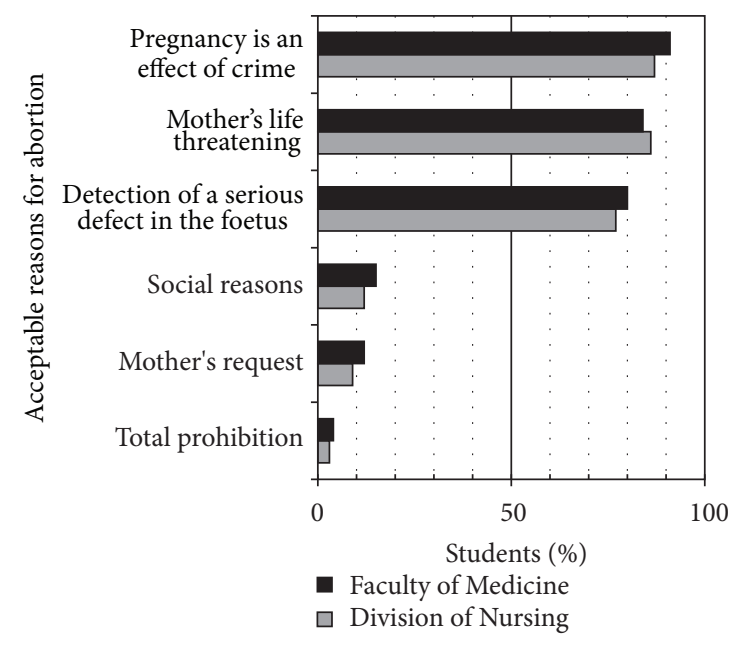

(a)

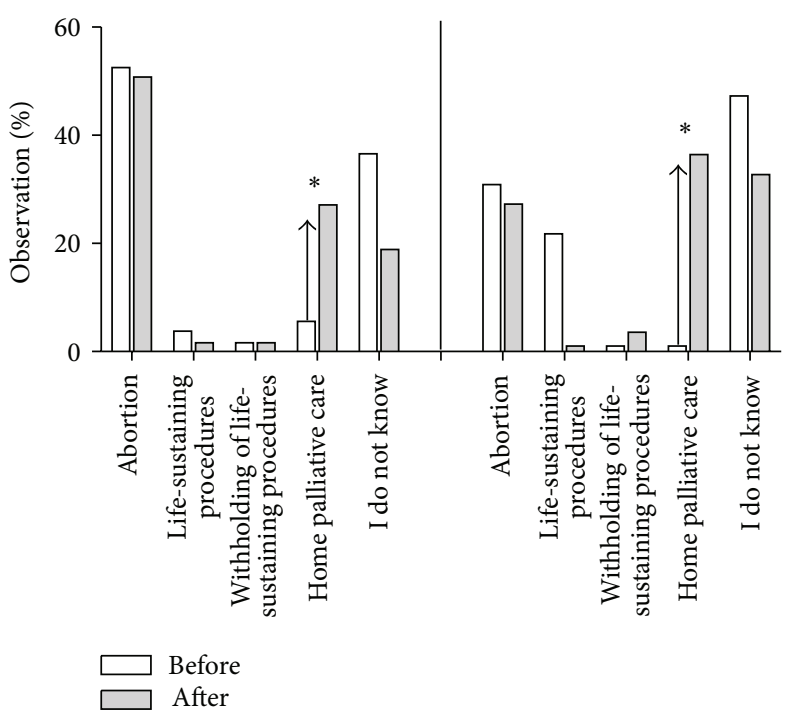

(b)

FIGURE 2: Students' opinion on specific problems of pediatric palliative care. (a) Percentage of respondents acceptable reasons for abortion. (b) The percentage of Faculty of Medicine students' (left panel) and Division of Nursing (right panel) students' declaring choice of particular management if a lethal defect was detected in their child. ${ }^{*} \mathrm{P}<0.05$. 


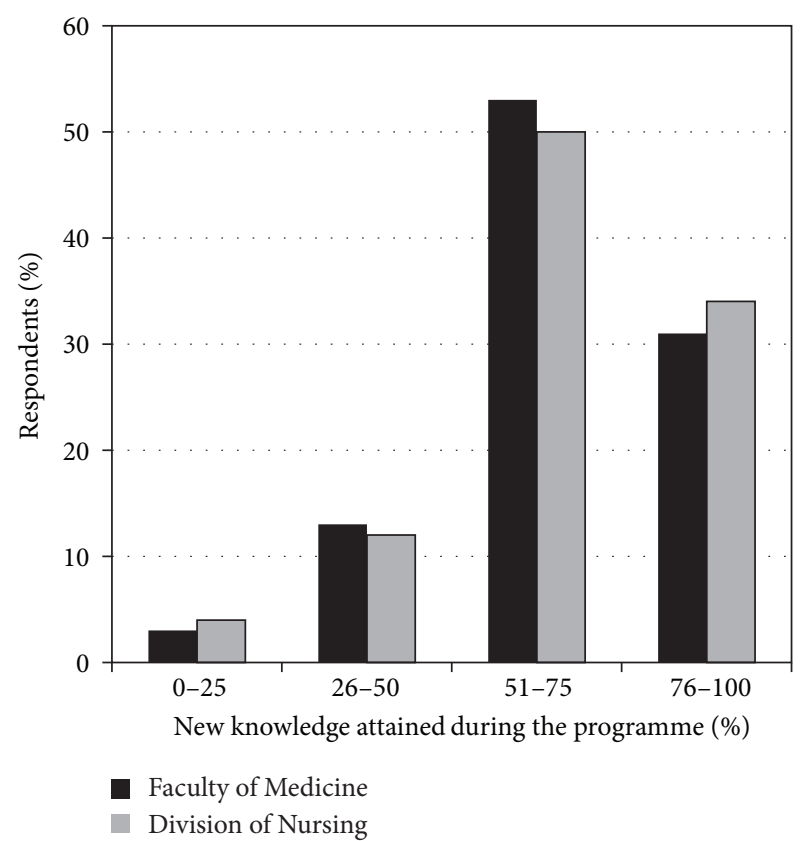

(a)

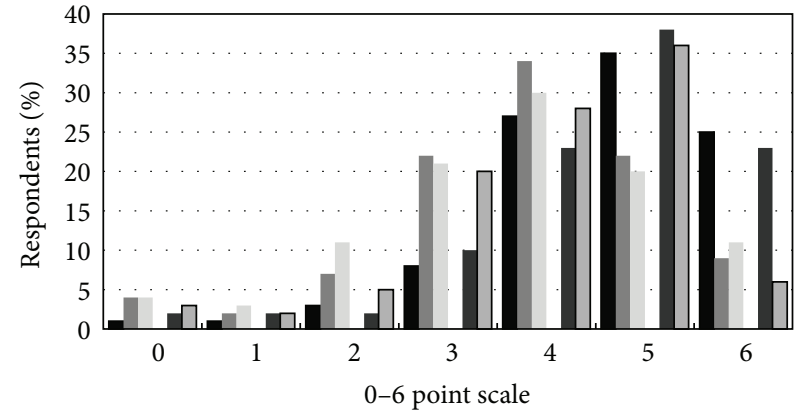
Future work (FM)
Future work (DN)
Final exam in pediatrics (FM)
$\square \quad$ Final exam in pediatrics (DN)
National medical exam (FM)
FM Faculty of Medicine students
DN Division of Nursing students

FIgURE 3: Students' opinion on knowledge attained during the programme. (a) Evaluation of novelty of knowledge attained during the programme. (b) The usefulness of the new knowledge in students' future work and preparation for exams evaluated on 0-6-point scale.

usefulness on 0-6-point scale. The majority of students positively answered this question (5 and 6 points), Figure 3(b). The students unequivocally (95.2\% FM and 95.7\% DN) expressed the need to introduce palliative care of children into the pediatric curriculum during studies.

All the lectures and teachers were evaluated individually by students. All teachers had similar favorable ratings; their work was well received and graded on average of $5.26 \pm 0.52$. Additionally, individual evaluation of each teacher's domain showed mean results above 5 points.

Answering the opened questions, only 12 students expressed their negative opinion about the programme and suggested that the subjects were unnecessary. The students were given a chance to suggest the elements of the programme which needed modification. Most of students (80.1\% FM and $85.1 \% \mathrm{DN}$ ) said that the programme should be extended in terms of the amount of teaching hours; $66.9 \%$ FM of students wanted more workshop hours and $86.9 \%$ suggested a strong need for more psychological workshops. Additionally, $72 \%$ of FM and $82.9 \%$ of DN students expressed a need for patient's participation in the teaching.

\section{Discussion}

The authors of many reports stress the need of pre- and postgraduate training in palliative care [1-8]. Unfortunately very few studies have been devoted to education in PPCdiscipline which is very distinct from palliative care of adults $[9-11,15]$. The specific aspects of PPC lead to the fact that, in
Poland, PPC is carried out mainly by pediatricians and only in special cases by specialists in palliative medicine. Thus, naturally, PPC was integrated with pediatric curriculum. Low initial level of knowledge on PPC issues among students from both faculties and its significant improvement after classes are strong argument for the introduction of such classes into curriculum. The results are similar to observations from other authors, which confirm efficacy of such educational intervention $[2-8,16-18]$. The observed lower initial level of knowledge among DN students may result from the fact that the programme was carried out at the 3 rd year of studies, and not the 6 th year as it was the case for MF students. The profile of questions which were the most troublesome for students also confirms the need to incorporate PPC issues in the curriculum. The most difficult questions concerned basic clinical issues and this is a valuable comment for the authors of this research, especially in the light of our previous experience of providing PPC. In the last few years of providing hospice care, we have observed some lack of knowledge among the medical staff in terms of home based care and the rules of admitting patients. Very often, the referred children did not require palliative care but a long-term treatment, in cases such as cerebral palsy or encephalopathy. The problem of pain management is included in all PPC training programmes, and the participants almost always stress how insufficient their knowledge on this issue is [10, 19-21]. The observed differences in results between faculties may result from differences in teaching curricula.

Ethical and moral considerations in end-of-life care are an important element of PPC education [17, 22-25]. During 
workshops and lectures, issues specific for perinatal palliative care and euthanasia were discussed. The problem of students' attitude towards euthanasia has been a subject of many studies [26-32], but, in the available Polish literature, there are only a few reports [33-37]. The results of Polish studies published by Leppert et al. in 2005 and 2009 demonstrated that $82 \%$ and $58 \%$ of medical students, respectively, definitely rejected possibility of performing euthanasia act, while $6 \%$ and $29 \%$, respectively, were indecisive [33]. The questionnaires were distributed after classes on palliative care or bioethics. In the study by Mierzecki et al., conducted among 1st year students, almost 50\% declared acceptance of euthanasia [34]. Similar results were obtained by Reczek [35] and Erderle et al. [36]. The analysis of other authors' results indicates that students of higher years are less accepting towards euthanasia [28]. The results of our study only partially seem to confirm the above observation. Many authors claim that participation in classes on palliative care may also be the reason, but we did not analyze whether these students participated in classes on palliative care for adults before. The obtained results differ from those reported by some authors; however, influence of religious beliefs as the element of cultural differences among countries is always stressed. This may be the reason why in USA, The Netherlands, Greece, and Hungary most of the students supported euthanasia and physician-assisted suicide (PAS), but, in countries such as Norway, Sweden, Yugoslavia, Italy, Germany, Sudan, and Malaysia, most students expressed negative positions regarding euthanasia [38]. In the presented study, students' opinions on the introduction of legal regulations concerning euthanasia in Poland are interesting. More than $70 \%$ of DN students did not see possibility of euthanasia in their patients and were against the legalization of euthanasia, while $88 \%$ of FM students would not perform euthanasia act, but, at the same time, almost $60 \%$ support legalization of euthanasia if certain criteria are met. Euthanasia is illegal in Poland; thus, the above considerations are purely theoretical. However, we may claim that these attitudes result from, on the one hand, respect for patient's autonomy and his right to decide about his own life and, on the other hand, from granting the doctor, right to refuse performing a procedure against his philosophy of life (the so-called conscience clause, acceptable in the Polish law). In addition, it is noteworthy that, after the programme, the number of students in both faculties, who were opponents of legalization of euthanasia and PAS, significantly increased. These results are in contrast to those of Leppert, where supporters of euthanasia were by half less numerous [33]. It is possible that these differences resulted from the fact that answers to that question included also an option of euthanasia only after certain criteria have been fulfilled. In the study, general attitude towards euthanasia was confronted with hypothetical situation of individual management choice in perspective of an untreatable disease. Before classes, almost $40 \%$ of responders declared euthanasia or PAS in such case, but participation in the programme decreased significantly the number of persons declaring choice of the above options. Interpretation of the obtained results leads us to conclusions that discussions with students changed their stereotypic attitudes and helped to overcome individual fear of suffering and death, resulting from lack of knowledge. The observed change in the students' attitude may be regarded as an added value of the implemented educational programme, which is consistent with current tendencies in the preparation of curriculum for medical students.

As a result of the advancements in the prenatal methods of diagnosis, there is a relatively new area of PPC: perinatal palliative care. It applies to situations in which prenatal diagnosis suggests serious, untreatable pathology of the foetus. The current literature suggests that PPC programmes may be comprehensive, integrative and initiated early already during pregnancy $[38,39]$. Elements of perinatal palliative care have been introduced into the presented programme and during workshops issues connected with initiating special procedures or abortion, in particular in a situation of unfavorable prenatal diagnosis, were discussed. The majority of respondents accepted possibility of refraining from resuscitation in case of untreatable disease in a child, and these results are not surprising in the context of current legal regulations in Poland. Additionally, these problems are discussed during classes of pediatrics and ethics. Certain issues connected with abortion require additional discussion. The Polish law accepts abortion in 3 situations: (1) detection of a serious defect in the foetus, (2) if mother's life is threatened, or (3) pregnancy is an effect of crime. The majority of respondents accepted the above conditions. In the majority of reports, regardless of country of origin, there is consensus on abortion acceptance if mother's life is threatened, but the greatest differences, resulting probably from social and religious beliefs, concern abortion on mother's request [4044]. Similar to the problem of euthanasia, general attitude of responders to abortion was confronted with hypothetical necessity of decision making in a situation of prenatal diagnosis of a lethal defect in responder's own child. It seems that, after the programme, students perceive palliative care as an alternative to management showing features of aggressive persistent treatment for families who reject possibility of abortion. These observations are invaluable as they reflect the very ideas, aims, and principles of palliative care [38, 39].

The above presented educational programme was the first pilot initiative in the country and that is why student evaluation of the project is so crucial for the tutors. The respondents highly valued the programme. The presented results are similar to observations of other authors. Schiffman et al. [11] and Kato et al. [10] demonstrated in their studies that participants of PPC training positively evaluated the programme and its applicability. In the research conducted by Michelson et al. [45], residents reported mainly no or minimal training, knowledge, experience, comfort, and competence in palliative care communication and symptom management. Michelson et al. [45], Billings and Block [46] showed a preference for education via observation and participation in multidisciplinary groups.

In Poland, palliative care for children has been mainly provided by specialized pediatric palliative home care teams. Due to the logistics (the distance between the hospice's office and the children's homes varies from 15 to 100 kilometres) there was no possibility of bedside teaching; however, there is also a plan to open a hospice ward for children within the next 
two years. In the presented research, the students expressed a need for more teaching in psychology. Those observations confirm the results of other research. Previous studies have showed that palliative medicine is a rich area to provide teaching about other forms of medical practice to students such as the patient-doctor communication, relationship, caring, and empathy [9, 47-51].

There are some limitations to this study that should be kept in mind when interpreting the findings. Evaluation of the efficacy of training and changes in the students' attitudes was performed directly after completion of the programme. Thus, long-term influence of training on the level of knowledge and attitudes of respondents is difficult to determine. In future, a follow-up study should be considered, in order to properly evaluate the effects of training; however, performing of such a follow-up study may be difficult from the logistic point of view. The authors may have difficulties with distribution of the questionnaire among absolvents, who will have started working in various centres around Poland by then, and the university does not collect such data. Additionally, it should be remembered that the programme had a pilot character and the presented results should be considered as initial, serving as a starting point for future research.

The results presented indicate that the outcome of pilot paediatric palliative care educational programme was really feasible and well received by the students. Pregraduate educational intervention may improve cooperation of home hospice team with GPs and hospitals staff. However, the number of hours devoted to pediatric palliative care in the curriculum is short and some issues, especially psychological, are not covered enough.

\section{Conflict of Interests}

The authors have no conflict of interests to disclose.

\section{Acknowledgments}

The programme has been awarded and 90\% financed by the Foundation for the Development of the Education System, Measure V Edition, Development of the Polish Higher Education Institution. Since August 2009, the project has been completed with the support granted by Iceland, Liechtenstein, and Norway by means of cofinancing from the European Economic Area Financial Mechanism and the Norwegian Financial Mechanism, as a part of the Scholarship and Training Fund. Sponsor was not involved in the conduct of the study or development of the submission.

\section{References}

[1] J. Luczak, M. Okupny, and L. Wieczorek-Cuske, "The program of palliative medicine and care in the curriculum of sixth-year medical students in Poland," Journal of Palliative Care, vol. 8, no. 2, pp. 39-43, 1992.

[2] M. S. Ellman, J. R. Rosenbaum, E. Cherlin, and M. Bia, "Effectiveness of an integrated ward-based program in preparing medical students to care for patients at the end of life," The
American Journal of Hospice and Palliative Medicine, vol. 26, no. 1, pp. 18-23, 2009.

[3] S. R. Mason and J. E. Ellershaw, "Undergraduate training in palliative medicine: is more necessarily better?" Palliative Medicine, vol. 24, no. 3, pp. 306-309, 2010.

[4] S. R. Mason and J. E. Ellershaw, "Preparing for palliative medicine; evaluation of an education programme for fourth year medical undergraduates," Palliative Medicine, vol. 22, no. 6, pp. 687-692, 2008.

[5] J. F. Hammel, A. M. Sullivan, S. D. Block, and R. Twycross, "End-of-life and palliative care education for final-year medical students: a comparison of Britain and the United States," Journal of Palliative Medicine, vol. 10, no. 6, pp. 1356-1366, 2007.

[6] J. Gibbins, R. McCoubrie, J. Maher, B. Wee, and K. Forbes, "Recognizing that it is part and parcel of what they do: teaching palliative care to medical students in the UK," Palliative Medicine, vol. 24, no. 3, pp. 299-305, 2010.

[7] S. Yazdani, E. Evan, D. Roubinov, P. J. Chung, and L. Zeltzer, "A longitudinal method of teaching pediatric palliative care to interns: preliminary findings regarding changes in interns' comfort level," Palliative and Supportive Care, vol. 8, no. 1, pp. 35-40, 2010.

[8] M. Roth, D. Wang, M. Kim, and K. Moody, "An assessment of the current state of palliative care education in pediatric hematology/oncology fellowship training," Pediatric Blood and Cancer, vol. 53, no. 4, pp. 647-651, 2009.

[9] O. J. Z. Sahler, G. Frager, M. Levetown, F. G. Cohn, and M. A. Lipson, "Medical education about end-of-life care in the pediatric setting: principles, challenges, and opportunities," Pediatrics, vol. 105, no. 3, pp. 575-584, 2000.

[10] Y. Kato, M. Akiyama, F. Itoh, and H. Ida, "A study investigating the need and impact of pediatric palliative care education on undergraduate medical students in Japan," Journal of Palliative Medicine, vol. 14, no. 5, pp. 560-562, 2011.

[11] J. D. Schiffman, L. J. Chamberlain, L. Palmer, N. Contro, B. Sourkes, and T. C. Sectish, "Introduction of a pediatric palliative care curriculum for pediatric residents," Journal of Palliative Medicine, vol. 11, no. 2, pp. 164-170, 2008.

[12] T. Dangel, S. Fowler-Kerry, M. Karwacki, and J. Bereda, "An evaluation of a home palliative care programme for children," Ambulatory Child Health, vol. 6, no. 2, pp. 101-114, 2000.

[13] A. Korzeniewska, Ł. Przysło, E. Filipiak, and M. Stolarska, "Home hospice for children of Lodz region: experiences in first year of activity," Pediatria Polska, vol. 81, no. 11, pp. 806-811, 2006.

[14] T. Dangel, M. Murawska, W. Marciniak, and K. Dangel, "Pediatric palliative home care in Poland (2010)," Medycyna Paliatywna, vol. 3, pp. 129-150, 2011.

[15] A Guide to the Developement of Children's Palliative Care Services, Association for Children's Palliative Care, 3rd edition, 2009.

[16] K. Porter-Williamson, C. F. von Gunten, K. Garman, L. Herbst, H. G. Bluestein, and W. Evans, "Improving knowledge in palliative medicine with a required hospice rotation for thirdyear medical students," Academic Medicine, vol. 79, no. 8, pp. 777-782, 2004.

[17] I. C. Fineberg, N. S. Wenger, and L. Forrow, "Interdisciplinary education: evaluation of a palliative care training intervention for pre-professionals," Academic Medicine, vol. 79, no. 8, pp. 769-776, 2004. 
[18] A. M. Sullivan, A. G. Warren, M. D. Lakoma, K. R. Liaw, D. Hwang, and S. D. Block, "End-of-life care in the curriculum: a national study of medical education deans," Academic Medicine, vol. 79, no. 8, pp. 760-768, 2004.

[19] C. Schiessl, J. Gärtner, S. Wildfeuer et al., "Pain management in international curricula for undergraduate education in palliative medicine. A palliative education assessment tool (PEAT) analysis," Schmerz, vol. 26, no. 2, pp. 200-205, 2012.

[20] J. A. Paice, C. Erickson-Hurt, B. Ferrell et al., "Providing pain and palliative care education internationally," Journal of Supportive Oncology, vol. 9, no. 4, pp. 129-133, 2011.

[21] J. W. Childers and R. M. Arnold, “I feel uncomfortable 'calling a patient out": educational needs of palliative medicine fellows in managing opioid misuse," Journal of Pain and Symptom Management, vol. 43, no. 2, pp. 253-260, 2012.

[22] J. Ousager and H. Johannessen, "Humanities in undergraduate medical education: a literature review," Academic Medicine, vol. 85, no. 6, pp. 988-998, 2010.

[23] C. A. Moyer, L. Arnold, J. Quaintance et al., "What factors create a humanistic doctor? A nationwide survey of fourth-year medical students," Academic Medicine, vol. 85, no. 11, pp. 18001807, 2010.

[24] D. Bell and V. Crawford, “'murder or mercy?' An innovative module helping UK medical students to articulate their own ethical viewpoints regarding end-of-life decisions," Southern Medical Journal, vol. 104, no. 10, pp. 676-681, 2011.

[25] J. J. Fins, "The humanities and the future of bioethics education," Cambridge Quarterly of Healthcare Ethics, vol. 19, no. 4, pp. 518521, 2010.

[26] B. A. M. Hesselink, H. R. W. Pasman, G. van der Wal, M. B. M. Soethout, and B. D. Onwuteaka-Philipsen, "Education on endof-life care in the medical curriculum: students' opinions and knowledge," Journal of Palliative Medicine, vol. 13, no. 4, pp. 381$387,2010$.

[27] P. C. Gruber, C. D. Gomersall, G. M. Joynt et al., "Changes in medical students' attitudes towards end-of-life decisions across different years of medical training," Journal of General Internal Medicine, vol. 23, no. 10, pp. 1608-1614, 2008.

[28] K. E. Clemens, E. Klein, B. Jaspers, and E. Klaschik, "Attitudes toward active euthanasia among medical students at two German universities," Supportive Care in Cancer, vol. 16, no. 6, pp. 539-545, 2008.

[29] M. Karlsson, P. Strang, and A. Milberg, "Attitudes toward euthanasia among Swedish medical students," Palliative Medicine, vol. 21, no. 7, pp. 615-622, 2007.

[30] J. D. Boudreau, "Physician-assisted suicide and euthanasia: can you even imagine teaching medical students how to end their patients' lives?" Permanente Journal, vol. 15, no. 4, pp. 79-84, 2011.

[31] A. Á. del Río and M. L. Marván, “On euthanasia: Exploring psychological meaning and attitudes in a sample of Mexican physicians and medical students," Developing World Bioethics, vol. 11, no. 3, pp. 146-153, 2011.

[32] W. J. Stronegger, C. Schmölzer, É. Rásky, and W. Freidl, “Changing attitudes towards euthanasia among medical students in Austria," Journal of Medical Ethics, vol. 37, no. 4, pp. 227-229, 2011.

[33] W. Leppert, J. Łuczak, and P. Góralski, "Selected problems of palliative care and euthanasia in physicians and medical students views," Advances in Palliative Medicine, vol. 4, no. 2, pp. 67-76, 2005.
[34] A. Mierzecki, K. Rekawek, J. Swiatkowski et al., "Evaluation of attitude towards euthanasia expressed by first year medical students from Szczecin, Greifswald and Lund medical faculties," Annales Academiae Medicae Stetinensis, vol. 54, no. 1, pp. 164$169,2008$.

[35] L. Reczek, "Student medycyny Śląskiej Akademii Medycznej wobec problemu eutanazji," Psychoonkologia, vol. 2, pp. 37-50, 1998.

[36] J. Enderle, Z. Fizia, and A. Guzy, “Próba porównania stosunku do eutanazjiwśród studentów studiów medycznych i niemedycznych," Annales Academiae Medicae Stetinensis, vol. 34 suppl, pp. 261-267, 2002.

[37] V. Kontaxakis, K. G. Paplos, B. J. Havaki-Kontaxaki et al., "Attitudes on euthanasia and physician-assisted suicide among medical students in Athens," Psychiatrike, vol. 20, no. 4, pp. 305311, 2009.

[38] A. Balaguer, A. Martín-Ancel, D. Ortigoza-Escobar, J. Escribano, and J. Argemi, "The model of palliative care in the perinatal setting: a review of the literature," $B M C$ Pediatrics, vol. 12, article $25,2012$.

[39] C. Wool, "Systematic review of the literature: parental outcomes after diagnosis of fetal anomaly," Advances in Neonatal Care, vol. 11, no. 3, pp. 182-192, 2011.

[40] R. Steele, "Medical students' attitudes to abortion: a comparison between Queen's University Belfast and the University of Oslo," Journal of Medical Ethics, vol. 35, no. 6, pp. 390-394, 2009.

[41] M. Ben Natan and O. Melitz, "Nurses' and nursing students' attitudes towards late abortions," International Nursing Review, vol. 58, no. 1, pp. 68-73, 2011.

[42] G. H. Hagen, C. Ø. Hage, M. Magelssen, and P. Nortvedt, "Medisinstudenters holdninger til selvbestemt abort," Tidsskrift for den Norske Laegeforening, vol. 131, no. 18, pp. 1768-1771, 2011.

[43] R. L. Elliott, M. Chowdhury, L. Wilson, F. C. Dane, and S. Williams, "Does religion affect medical students' attitudes toward ethical dilemmas?" Journal of the Medical Association of Georgia, vol. 101, no. 2, pp. 22-23, 2012.

[44] R. D. de Medeiros, G. D. de Azevedo, E. A. A. de Oliveira et al., "Opinion of medical and law students of Federal University of Rio Grande do Norte about abortion in Brazil," Revista Brasileira de Ginecologia e Obstetricia, vol. 34, no. 1, pp. 16-21, 2012.

[45] K. N. Michelson, A. D. Ryan, B. Jovanovic, and J. Frader, 'Pediatric residents' and fellows' perspectives on palliative care education," Journal of Palliative Medicine, vol. 12, no. 5, pp. 451457, 2009.

[46] J. A. Billings and S. Block, "Palliative care in undergraduate medical education: status report and future directions," Journal of the American Medical Association, vol. 278, no. 9, pp. 761-763, 1997.

[47] C. Coles, "Undergraduate education and palliative care," Palliative Medicine, vol. 10, no. 2, pp. 93-98, 1996.

[48] M. Lloyd-Williams and N. Dogra, "Caring for dying patients: what are the attitudes of medical students?" Supportive Care in Cancer, vol. 11, no. 11, pp. 696-699, 2003.

[49] D. Bell and V. Crawford, “'murder or mercy?' an innovative module helping UK medical students to articulate their own ethical viewpoints regarding end-of-life decisions," Southern Medical Journal, vol. 104, no. 10, pp. 676-681, 2011.

[50] Y. Kizawa, S. Tsuneto, K. Tamba et al., "Development of a nationwide consensus syllabus of palliative medicine for undergraduate medical education in Japan: a modified Delphi method," Palliative Medicine, vol. 26, no. 5, pp. 744-752, 2012. 
[51] E. M. Wittenberg-Lyles, J. Goldsmith, S. L. Ragan, and S. Sanchez-Reilly, "Medical students' views and ideas about palliative care communicatio training," The American Journal of Hospice and Palliative Medicine, vol. 27, no. 1, pp. 38-49, 2010. 


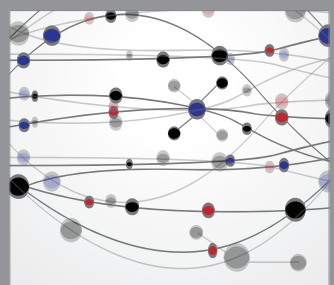

The Scientific World Journal
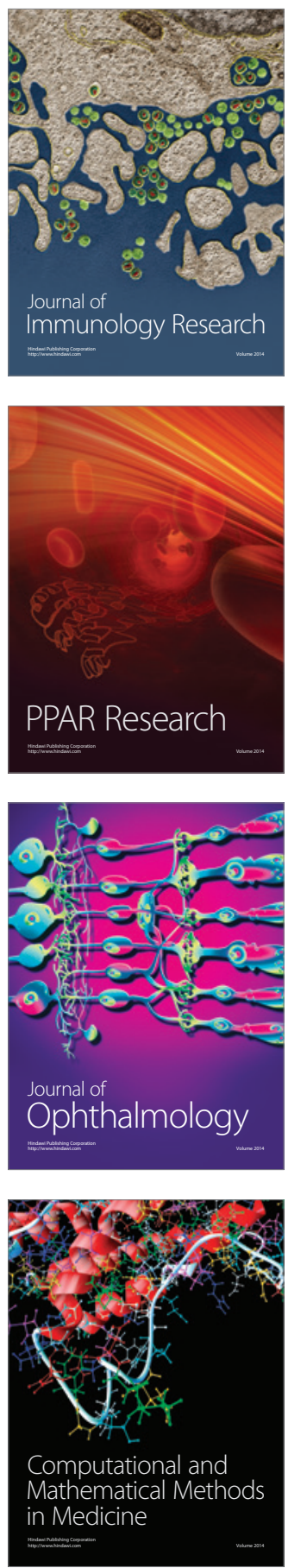

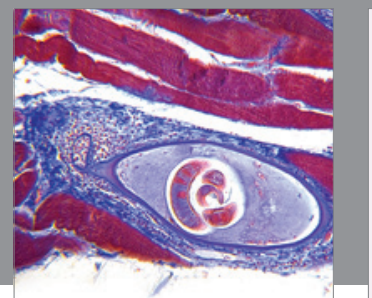

Gastroenterology

Research and Practice
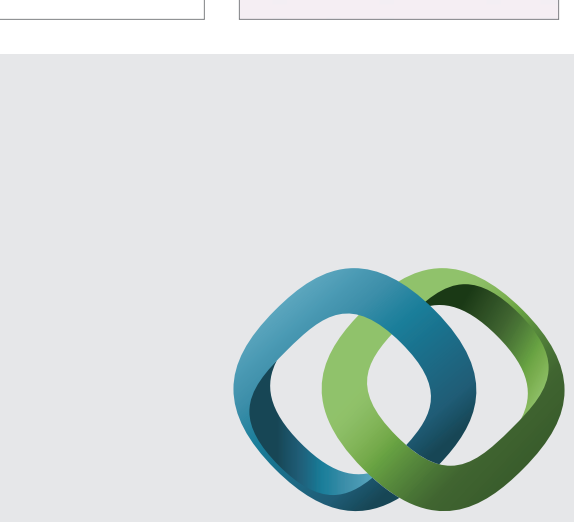

\section{Hindawi}

Submit your manuscripts at

http://www.hindawi.com
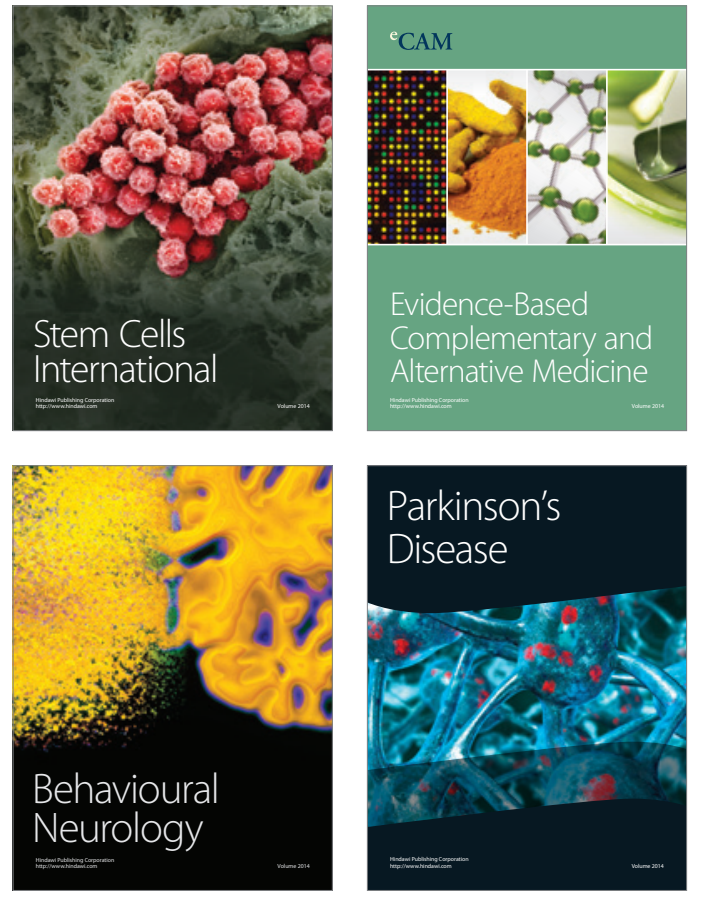
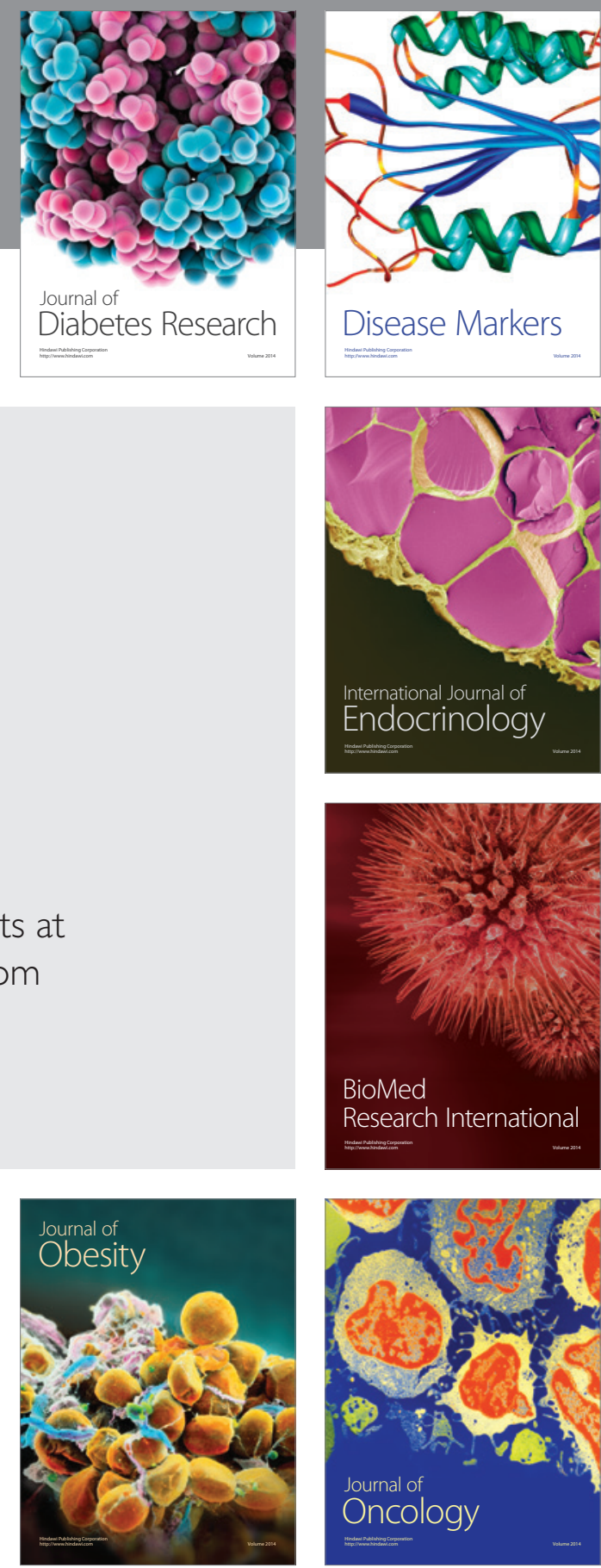

Disease Markers
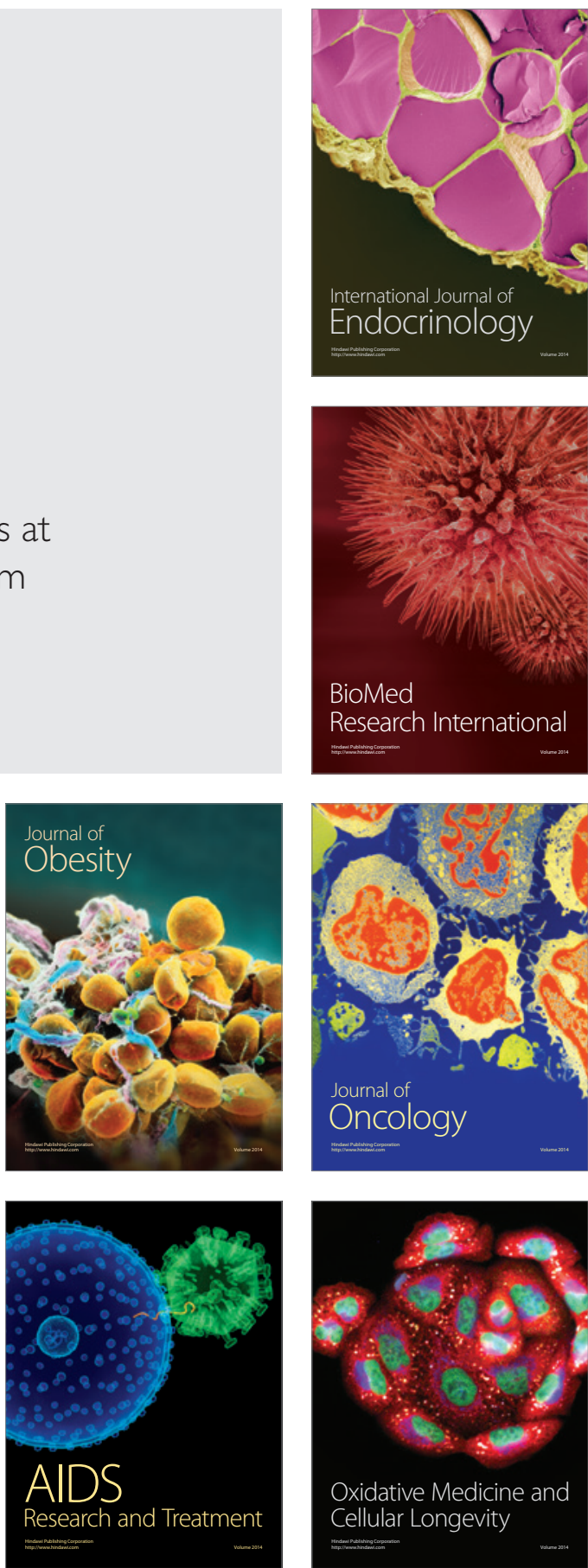